\title{
SUPPLEMENTATION OF VITAMIN E 400 IU DECREASES MALONDIALDEHYDE LEVEL OF OBESE WOMEN STAFF AT SCHOOL OF MEDICINE UDAYANA UNIVERSITY
}

\author{
LUH PUTU RATNA SUNDARI*, NYOMAN ADIPUTRA, I MADE KRISNA DINATA
}

Department of Physiology, School of Medicine, Udayana University, Bali, Indonesia. Email: ratnabudhiyasa@gmail.com

Received: 26 April 2017, Revised and Accepted: 24 May 2017

\section{ABSTRACT}

Objective: Increasing of adipose tissue in obesity make an inflammation cellular due to stress oxidative. Malondialdehyde (MDA) is produced by that cellular reaction and used as indicator peroxidation lipid reaction in many tissues. Vitamin E will inhibit lipid peroxidation reaction. This study is about the effectiveness of vitamin $\mathrm{E}$ to decrease the MDA level in obesity women.

Methods: The pre- and post-test control group design study was conducted on 24 female obese women. Subjects were divided into two groups randomly with 12 women each group. Control group was given placebo capsules, and the experimental group was given vitamin E capsules 400 IU for 30 days. MDA level was measured before and after treatment, analyzed by independent t-test and the p<0.05 was considered significant.

Results: The decreasing of MDA level of the control group was $1.601 \pm 0.313 \mu \mathrm{mol} / \mathrm{ml}$, and experimental group was $2.161 \pm 0.471 \mu \mathrm{mol} / \mathrm{ml}$. From post-test result comparison, the experimental group shows a significant decrease $(\mathrm{p}<0.05)$ of MDA level.

Conclusion: Vitamin E supplementation can decrease MDA level in obese women staff at School of Medicine Udayana University.

Keywords: Vitamin E, Lipid peroxide, Malondialdehyde, Obesity.

(C) 2017 The Authors. Published by Innovare Academic Sciences Pvt Ltd. This is an open access article under the CC BY license (http://creativecommons. org/licenses/by/4. 0/) DOI: http://dx.doi.org/10.22159/ajpcr.2017.v10i9.19400

\section{INTRODUCTION}

Obesity is complex and the chronological disease that affects millions of people worldwide and contributes substantial morbidity and mortality [1]. Obesity has become a major health problem worldwide, affecting people across all ages, sex, ethnicities, and races. Prevalence of obesity was higher in urban than rural people with significant increases in obesity rates among women [2]. In an urban area, most women work in sedentary activity such as office staff that will increase obese risk. Obesity is not just a condition with the amount of excess fat deposit, but also about the distribution of fat throughout the body. The distribution of fat may increase the risk of obesity that associated with various degenerative diseases [3]. Excess fat in adipose tissue will increase oxidation process. Oxidation in adipose tissue inhibits cell oxygenation that leads to molecular inflammation in the tissue, which activating macrophages and vascular endothelial cells leading to cellular inflammation [4]. Increasing the amount of fat will increase the oxidation process, which leads to oxygen dysfunction and resulting more inflammation. Inflammation is a source of oxidative stress.

Oxidative stress is a condition in which an increase in reactive oxygen species (ROS) will cause cell, tissue or organ damage. High concentration of ROS and free radicals damage deoxyribonucleic acid, proteins, carbohydrates and lipid constituent, and compromise cell function $[2,5]$. Under conditions of oxidative stress, free radicals will cause cell membrane lipid peroxidation and damage the organization of cell membranes. This cell membrane is essential for the function of the receptor and the function of the enzyme. Peroxidations of lipid cell membranes by free radicals can loss of cellular function. Lipid peroxidation is a mechanism of cellular trauma, both in plants and animals, thus lipid peroxidation is used as an indicator of oxidative stress in cells and tissues [6].

One of the compounds that produced by lipid peroxide reaction is malondialdehyde (MDA). MDA is formed by the degradation of hydroxyl $(\mathrm{OH})$ free radicals to unsaturated fatty acids, which are later transported into highly reactive free radical. Therefore, MDA measurement is often used as an indicator of tissue lipid peroxidation [6]. Increased oxidative stress will increase MDA levels. Oxidative stress in the body can be suppressed by antioxidant. Antioxidant is a substance that can neutralize free radicals and prevents harmful effect to the body's biological system from excessive oxidation reactions [7]. It was suggested, antioxidant as a neutralizing agent of free radicals has known as enzymes, and some are micronutrients. Antioxidant enzymes which are formed in the body such as superoxide dismutase, glutathione peroxidase, catalase, and glutathione reductase. Meanwhile, antioxidant from micronutrients has known as three major kinds such as beta-carotene, vitamin $\mathrm{C}$, and vitamin E [8]. Beta-carotene is single oxygen scavengers, vitamin C is superoxide scavengers and other free radicals, and vitamin $\mathrm{E}$ is a fat peroxide chain breaker in cell membranes. Vitamin $\mathrm{E}$ is found in lipoproteins, cell membranes and extracellular fluids. Fat-soluble vitamin $\mathrm{E}$ is an antioxidant that protects polyunsaturated fatty acids and cell components and cell membranes from oxidation by free radicals. It controls the fat peroxide by donating hydrogen into the reaction, and block additionally peroxide activities thus breaking the chain reaction and limiting the damage [9].

Based on the antioxidant ability of vitamin E, the authors are interested to know the effects of vitamin $\mathrm{E}$ in reducing oxidative stress of obese women staff.

Table 1: Patients characteristics data

\begin{tabular}{llll}
\hline Variable & \multicolumn{2}{l}{ Group } & p \\
\cline { 2 - 3 } & Placebo & Vitamin E & \\
\hline Age (years) & $40.91 \pm 6.38$ & $39.67 \pm 6.53$ & 0.650 \\
Weight $(\mathrm{kg})$ & $68.36 \pm 4.27$ & $72.25 \pm 9.14$ & 0.152 \\
Height $(\mathrm{cm})$ & $154.36 \pm 6.98$ & $157.50 \pm 3.37$ & 0.178 \\
BMI $\left(\mathrm{kg} / \mathrm{m}^{2}\right)$ & $27.22 \pm 1.79$ & $29.04 \pm 3.30$ & 0.062 \\
\hline $\mathrm{n}=12$ each group. BMI: Body mass index & &
\end{tabular}


Table 2: MDA level of two groups

\begin{tabular}{llllll}
\hline Group & $\mathbf{n}$ & \multicolumn{2}{l}{ Mean of MDA $(\boldsymbol{\mu m o l} / \mathbf{m l})$} & \multirow{2}{*}{ Mean changes of MDA level $(\boldsymbol{\mu m o l} / \mathbf{m l})$} & $\mathbf{p}$ \\
\cline { 2 - 4 } & & Pre-treatment & Post-treatment & & $0.003^{*}$ \\
\hline Placebo & 12 & $6.326 \pm 1.177$ & $4.726 \pm 1.068$ & $1.601 \pm 0.313$ & \\
Vitamin E & 12 & $6.962 \pm 1.019$ & $4.087 \pm 0.862$ & $2.161 \pm 0.471$ & \\
\hline
\end{tabular}

*Unpaired t-test. MDA: Malondialdehyde

\section{METHODS}

The study was conducted in the Department of Physiology, School of Medicine, Udayana University take place during June to September 2016. Subjects were enrolled from all women staff at School of Medicine Udayana University who suffered from obesity after taking ethical clearance from Ethics Committee of the School of Medicine, Udayana University. The inclusion criteria of the population study are informed consent, obese woman (body mass index [BMI] $>25 \mathrm{~kg} / \mathrm{m}^{2}$ ), age 25-45 years and no pathological history or chronic disease. Women with history taking any medication known to influence metabolic and immune system, vitamin supplement and another antioxidant 1 week before research, vegetarian, and follow training program were excluded. Drop out categorized if the subject could not complete the vitamin E treatment. The sample size is determined by the Pocock formula. Based on the previous study, the sample size was calculated with alpha error of 0.5 and power of $80 \%$. A sample size power calculation determined that 12 patients were needed in each group. Total 24 women were selected. They were placed into two groups (experimental and control group) with simple random sampling. All of them had joined the study involuntarily based and given informed consent.

The experimental group received vitamin E capsules 400 IU once daily. The control group received a placebo drug. Patients came every day and nurse registered patients and delivered the drugs to the patients. The venous blood sample was collected twice, before and after treatment. Level of MDA in blood was measured with enzyme-linked immunosorbent assay standard kit, and the results were compared between the groups. The data obtained were statistically analyzed by independent $\mathrm{t}$-test and the $\mathrm{p}<0.05$ was considered significant.

\section{RESULTS}

Data were summarized as mean \pm standard deviation. Groups were compared by independent Student's t-test. A two-sided $(\alpha=2) \mathrm{p}<0.05$ was considered statistically significant. All analysis was performed on SPSS (version 17.0) software.

The study evaluates the effect of oral administration of vitamin E 400 IU on MDA level of obese women. There was no statistically significant difference in basic parameter among subjects of two groups (Table 1). In other words, subjects of two groups were matched and comparable.

After 1 month of vitamin E supplementation, the mean level of MDA was found lower in vitamin E group. Mean changes of MDA level before and after treatment higher in group vitamin E compared to group placebo significantly $(\mathrm{p}=0.003)$ (Table 2$)$.

\section{DISCUSSION}

There are several possible contributors to oxidative stress in obesity including hyperglycemia, increased muscle activity to carry excessive weight, elevated tissue lipid levels, chronic inflammation, endothelial ROS production, hyperleptinemia, and inadequate antioxidant defenses [9]. These factors are not mutually exclusive, obesity may involve some or all of these contribute to systemic oxidative stress. Inadequacy of antioxidant defenses may begin with a low intake of protective antioxidants and phytochemicals in diet [10]. In previous research was found a significant reduction in antioxidant enzymes activity and glutathione level in almost all tissue of high-fat feeding mice compared with non-fat animals. On the other hand, non-enzymatic oxidative stress parameters lipid peroxidation markers MDA and protein oxidation markers level increased in these tissues. Increased MDA levels by the effects of high-fat diet were normalized in all tissues except the kidney with vitamin E [11]. This is in accordance with our results that vitamin $\mathrm{E}$ can decrease MDA levels in obese woman staff.

All the subjects in this study had BMI $>25 \mathrm{~kg} / \mathrm{m}^{2}$, based on obese criteria of Asia Pacific BMI category. In the previous study, serum levels of dietary antioxidants (beta-carotene, vitamin $\mathrm{E}$ and $\mathrm{C}$ ) were found to be lower in obese than non-obese and supplementation of vitamin E will help to maintain the lack of vitamin and antioxidants in obesity and may be effective in suppressing multiple oxidative pathways to obesity-induced disease [12]. Vitamin E ( $\alpha$-tocopherol) a natural antioxidant is known to be used to treat and prevent the diseases [13]. Supplementation of vitamin E in this study is also supported by the previous research about antioxidant levels in obese women. This research showed that vitamin $\mathrm{E}$ levels in obese women $(0.70 \pm 0.10 \mathrm{mg} / \mathrm{dl})$ are lower than healthy women $(0.87 \pm 0.16 \mathrm{mg} / \mathrm{dl}), \mathrm{p}<0.05$. It means that obese women need vitamin E supplementation [14].

In this study, after 1 month supplementation, mean change in MDA level was higher in group vitamin $\mathrm{E}$ than group placebo. Vitamin $\mathrm{E}$ is controlling the lipid peroxide by donating hydrogen into the reaction, blocks the additional activity performed by peroxides, thus breaking the chain reaction and limiting the damage. That reaction will decrease MDA level as a product from lipid peroxide reaction [6].

Other research also support that vitamin E supplementation in human subjects and animal models has been shown to decrease lipid peroxidation, superoxide (02-) production by impairing the assembly of nicotinamide adenine dinucleotide phosphate (reduced form) oxidase as well as by decreasing the expression of scavenger receptors (SR-A and CD36), particularly important in the formation of foam cells [15]. Vitamin E action over peroxidation was able to enhance the antioxidant defense of both glutathione-related enzymes. These data support that antioxidant supplementation produces a protective effect on the oxidative damage induced by obesity [16]

\section{CONCLUSION}

Supplementation of vitamin E 400 IU for 30 days can decrease MDA level in obese women staff School of Medicine Udayana University. It will support the usage of vitamin $\mathrm{E}$ as a supportive treatment to reduce oxidative stress in obesity. However, to achieve more confirmatory results further study on larger sample size is needed.

\section{ACKNOWLEDGMENTS}

This study was supported by research and development department, school of medicine, Udayana University.

\section{REFERENCES}

1. Durga GL, Jhansi CH, Ram VR, Nadendla RR. An epidemiological survey on prevalence of obesity and diseases burden in common public. Int J Pharm Pharm Sci 2014;6(2):320-2.

2. Bollapragada MK, Shantaram M, Kumar S. Obesity: Development, epidemiology, factors affecting, quantity, health hazards, management and natural treatment-a review. Int J Pharm Pharm Sci 2017;9(2):12-26. 
3. Dixon JB. The effect of obesity on health outcomes. Mol Cell Endocrinol 2010;316:104-8.

4. Cancello R, Clément K. Is obesity an inflammatory illness? Role of low-grade inflammation and macrophage infiltration in human white adipose tissue. BJOG 2006;113(10):1141-7.

5. Kale MA, Bindu SM, Khadkikar P. Role of antioxidants and nutrition in oxidative stress: A review. Int J Appl Pharm 2015;7(1):1-4.

6. Halliwell B, Whiteman M. Measuring reactive species and oxidative damage in vivo and in cell culture: How should you do it and what do the results mean? Br J Pharmacol 2004;142(2):231-55.

7. Kris-Etherton PM, Lichtenstein AH, Howard BV, Steinberg D, Witztum JL. Nutrition Committee of the American Heart Association Council on Nutrition, Physical Activity, et al. Antioxidant vitamin supplements and cardiovascular disease. Circulation 2004;110(5):637-41.

8. Packer L. Protective role of vitamin E in biological systems. Am J Clin Nutr 1991;53 4 Suppl:1050S-5.

9. Vincent HK, Taylor AG. Biomarkers and potential mechanisms of obesity-induced oxidant stress in humans. Int $\mathrm{J}$ Obes (Lond) 2006;30(3):400-18.

10. Vincent HK, Bourguignon C, Taylor AG. Relationship between the newly proposed dietary phytochemical index, obesity and oxidative stress in young healthy adults. J Hum Nutr Diet 2010;23(1):20-9.
11. Aydin B. The effects of capsaicin and vitamin E on high fat diet induced obesity, hyperlipidemia and oxidative stress in different organs of mice. J Food Nutr Res 2015;3(6):357-64.

12. Viroonudomphol D, Pongpaew P, Tungtrongchitr R, Changbumrung S, Tungtrongchitr A, Phonrat $\mathrm{B}$, et al. The relationships between anthropometric measurements, serum vitamin $\mathrm{A}$ and $\mathrm{E}$ concentrations and lipid profiles in overweight and obese subjects. Asia Pac J Clin Nutr 2003;12(1):73-9.

13. Sukantha TA, Sripathi SK, Ravindran NT, Balashanmugam P. Antioxidant and antibacterial activities of Trianthema decandra Linn. Int J Pharm Pharm Sci 2012;4:410-3.

14. Singh K, Singh S. Comparative study on malondialdehyde and certain antioxidants in North West obese Indians. J Cardiovasc Dis Res 2015;6(3):138-44.

15. Devaraj S, Tang R, Adams-Huet B, Harris A, Seenivasan T, de Lemos JA, et al. Effect of high-dose alpha-tocopherol supplementation on biomarkers of oxidative stress and inflammation and carotid atherosclerosis in patients with coronary artery disease. Am J Clin Nutr 2007;86(5):1392-8.

16. Alcalá M, Sánchez-Vera I, Sevillano J, Herrero L, Serra D, Ramos MP, et al. Vitamin $\mathrm{E}$ reduces adipose tissue fibrosis, inflammation, and oxidative stress and improves metabolic profile in obesity. Obesity (Silver Spring) 2015;23(8):1598-606. 